\title{
Short-Run Dynamics between Urban Housing Markets: Toda-Yamamoto Tests
}

Gao- lu Zou*

College of Tourism, Economic, and Culture, Chengdu University, Chengdu 610106, China

\author{
Article History \\ Received: 28.10 .2020 \\ Accepted: 10.11 .2020 \\ Published: 14.11.2020
}

Journal homepage:

https://www.easpublisher.com/easmb

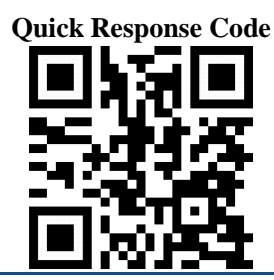

Abstract: Similar fundamentals such as geography, population, transport, trade and macro-policy may produce dynamics between commodity prices across cities. This study tested for the short-run dynamics between new home prices in Xi'an and Lanzhou. We used the Toda-Yamamoto technique, which does not depend on the property of unit root and cointegration. Data were monthly changes. The period is from 2006M01-2015M12. A feedback effect was suggested. In the short run, geographical diversification for housing properties can be achieved between these two Northwest China's metropolises. Keywords: Dynamics, housing, price, short run, Granger causality, levels VAR.

Copyright (C) 2020 The Author(s): This is an open-access article distributed under the terms of the Creative Commons Attribution 4.0 International License (CC BY-NC 4.0) which permits unrestricted use, distribution, and reproduction in any medium for non-commercial use provided the original author and source are credited.

\section{INTRODUCTION}

Xi'an and Lanzhou are the capitals of Shanxi Province and Gansu Province, respectively. Xi'an and Lanzhou are two cities located in the inland area of northwest China, and both were the main cities on the ancient Silk Road. Xi'an had been one of the most important capitals in ancient China. The economic and social development of the two major cities has been quick in recent years. But compared to other big cities in China, such as Chengdu, Chongqing, Suzhou, Guangzhou, and Nanjing, they are lagging behind. Despite this, the real estate economy is still growing rapidly. The distance between these two cities is 500 $\mathrm{km}$. Because the two cities are geographically close to each other, people migrate frequently between two cities. Housing markets are likely to contain short-run dynamics that drive each other's market. The dynamics will help the formation of a long-term equilibrium. City and regional housing markets appear to impact each other [1-5]. This paper tested for the short-run effects between new housing markets in Xi'an and Lanzhou.

\section{Methodology}

To examine the short-run dynamics between time series, we can conduct a Granger causality test. In general, we need to test for unit root and cointegration and constructing a linear error-correction model (ECM) given the existence of cointegration, or a linear vector autoregressive model (VAR) given the nonexistence of no cointegration between I(1) series.

Instead, we can drive the Granger causality test using the Toda-Yamamoto lag-augmented VAR technique [6]. Toda and Yamamoto [6] argue that this technique is free of dependence on the property of unit root in data and cointegration between integrated variables. A bivariate Toda-Yamamoto lag-augmented levels VAR is written as:

$$
y_{t}=\delta_{0}+\delta_{1} t+\beta_{1} x_{t 1}+. .+\beta_{k} x_{t k}+\beta_{k+1} x_{t(k+1)}+. .+\beta_{k+d} x_{t(k+d)}+\varepsilon_{t}
$$

Where the order of integration of $y_{t}$ and $x_{t}$ is at most two (denoted $\mathrm{d} \leq 2$ ) around a linear trend $(\mathrm{t}) . \varepsilon_{\mathrm{t}}$ is assumed to be i.i.d. We tested the null hypothesis of no Granger causality using Wald- $\chi^{2}[7]$ :

$$
H_{0}: \beta_{1}=\beta_{2} \ldots=\beta_{k}=0
$$


We tested for unit root using the ADF and PP tests to examine the order in data $[8,9]$.

\section{DATA}

Data was the monthly new commodity house price index as compared with the same month of last year. for the period from January 2006 to December 2015. Two time series are new house prices in Lanzhou
(HP_LANZHOU) and new house prices in Xi'an (HP_XIAN). Data were from NBSC [10]. We seasonally adjusted monthly series using the X-12 technique. Data were in logarithms. Data have non-zero means (Table 1) and have moved smoothly over time (Figure 1). We accepted the normality for HP_XIAN and HP_LANZHOU at the $10 \%$ level.

Table-1: Statistics for house prices

\begin{tabular}{|l|l|l|}
\hline Definition & \multicolumn{1}{|c|}{ New house prices in Xi'an } & New house prices in Lanzhou \\
\hline Variable & HP_XIAN & HP_LANZHOU \\
\hline Mean & 4.65 & 4.65 \\
\hline Median & 4.65 & 4.65 \\
\hline Maximum & 4.75 & 4.76 \\
\hline Minimum & 4.54 & 4.55 \\
\hline Std. Dev. & 0.05 & 0.04 \\
\hline Skewness & -0.06 & -0.25 \\
\hline Kurtosis & 2.36 & 2.73 \\
\hline Jarque-Bera & 2.12 & 1.59 \\
\hline Probability & 0.35 & 0.45 \\
\hline
\end{tabular}

Notes: The log of new house price indices as compared with the same of last year. Seasonally adjusted (X-12, multiplicative).

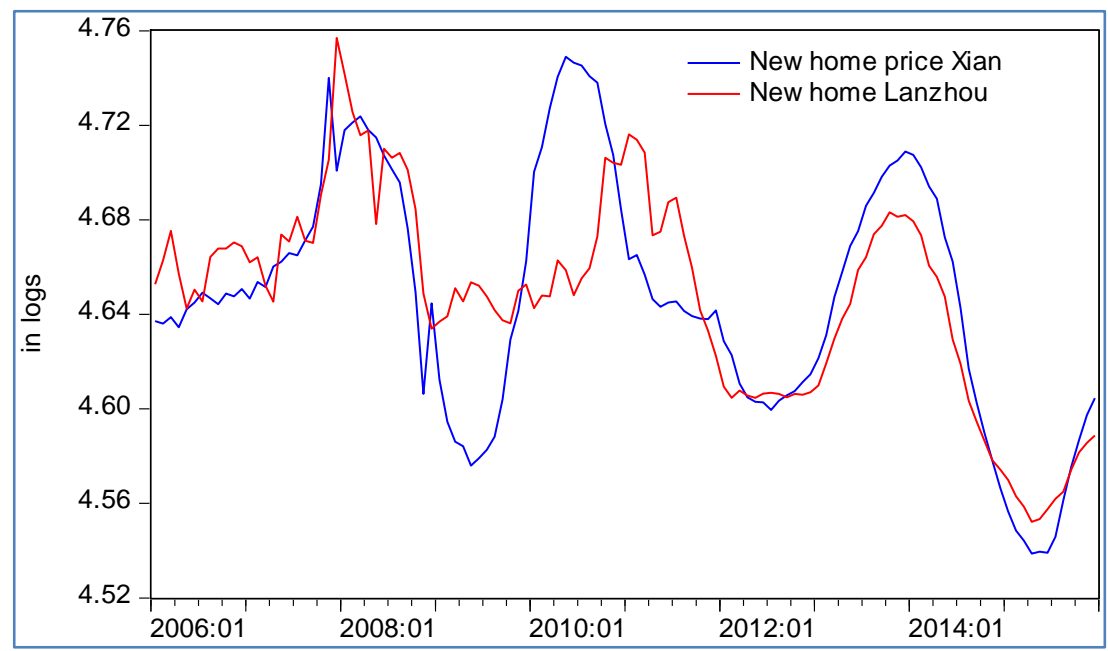

Fig-1: New house prices in Xian and Lanzhou, China (2006.01-2015.12)

\section{EMPIRICAL RESUlts}

The ADF, PP tests consistently showed that HP_LANZHOU and HP_XIAN were I(1) (Table 2). Thus, HP_LANZHOU I(1). HP_XIAN $\sim \mathrm{I}(1)$. We can estimate Toda-Yamamoto levels $\operatorname{VAR}(k+1)$ models to test for non-Granger causality (Table 3 and Table 4).
Table 5 reports the results of Granger causality based on the estimated VARs. At the 1\% level, we rejected all the null hypothesis of non-Granger causality. Thus, HP_LANZHOU Granger caused HP_XIAN and vice versa, indicating that a feedback effect exists between two home markets.

Table-2: The unit root tests

\begin{tabular}{|l|l|l|l|l|l|}
\hline Log variable & Methods & $\mathbf{k}$ & Level & $\mathbf{k}$ & First dif. \\
\hline HP_XIAN & ADF & 12 & -1.33 & 12 & $-4.15^{* * *}$ \\
\hline HP_LANZHOU & & 12 & -1.35 & 11 & $-4.45^{* * *}$ \\
\hline HP_XIAN & PP & 8 & -2.43 & 8 & $-9.13^{* * *}$ \\
\hline HP_LANZHOU & & 4 & -1.65 & 1 & $-9.11^{* * *}$ \\
\hline
\end{tabular}

Notes: $\mathrm{k}$ is the lag length. $\mathrm{k}$ between 1 and 12 [11]. Tests selected $\mathrm{k}$ using the t-statistic for ADF tests, the Newey-West method for PP tests. Intercept only [12]. ***Significance at the $1 \%$ level. 
Gao- lu Zou; East African Scholars Multidiscip Bull; Vol-3, Iss-11 (Nov, 2020): 316-319

Table-3: VAR estimation for Toda-Yamamoto testing (Dependent: HP_XIAN)

\begin{tabular}{|l|l|l|l|l|}
\hline Lagged term & Coefficient & Std. Error & t-Statistic & p-value \\
\hline HP_LANZHOU(-1) & 0.14 & 0.10 & 1.37 & 0.17 \\
\hline HP_LANZHOU(-2) & -0.18 & 0.14 & -1.24 & 0.22 \\
\hline HP_LANZHOU(-3) & -0.03 & 0.13 & -0.20 & 0.85 \\
\hline HP_LANZHOU(-4) & 0.23 & 0.13 & 1.81 & 0.07 \\
\hline HP_LANZHOU(-5) & -0.10 & 0.12 & -0.82 & 0.42 \\
\hline HP_LANZHOU(-6) & 0.41 & 0.12 & 3.46 & 0.00 \\
\hline HP_LANZHOU(-7) & -0.62 & 0.12 & -5.01 & 0.00 \\
\hline HP_LANZHOU(-8) & 0.36 & 0.14 & 0.01 \\
\hline HP_LANZHOU(-9) & -0.11 & 0.15 & 2.53 & 0.47 \\
\hline HP_LANZHOU(-10) & -0.09 & 0.10 & -0.72 & 0.35 \\
\hline HP_XIAN(-1) & 0.80 & 0.11 & -0.94 & 0.00 \\
\hline HP_XIAN(-2) & 0.03 & 0.16 & 7.51 & 0.85 \\
\hline HP_XIAN(-3) & 0.29 & 0.15 & 0.19 & 0.06 \\
\hline HP_XIAN(-4) & 0.09 & 0.13 & 1.90 & 0.48 \\
\hline HP_XIAN(-5) & -0.20 & 0.13 & 0.71 & 0.12 \\
\hline HP_XIAN(-6) & -0.04 & 0.13 & -1.59 & 0.79 \\
\hline HP_XIAN(-7) & -0.30 & 0.13 & -0.27 & 0.02 \\
\hline HP_XIAN(-8) & 0.06 & 0.13 & -2.31 & 0.67 \\
\hline HP_XIAN(-9) & -0.02 & 0.13 & 0.43 & 0.91 \\
\hline HP_XIAN(-10) & 0.07 & -0.12 & 0.52 \\
\hline t & 0.00 & 0.11 & 0.64 & 0.11 \\
\hline Constant & 0.90 & 0.00 & -1.62 & 0.00 \\
\hline
\end{tabular}

Notes: Adjusted R-squared=0.97, AIC=-6.46, F-statistic=197.5, DW=1.92.

Table-4: VAR estimation for Toda-Yamamoto testing (Dependent: HP_LANZHOU)

\begin{tabular}{|l|l|l|l|l|}
\hline Lagged term & Coefficient & Std. Error & t-Statistic & p-value \\
\hline HP_XIAN(-1) & 0.73 & 0.11 & 6.51 & 0.00 \\
\hline HP_XIAN(-2) & -0.52 & 0.16 & -3.19 & 0.00 \\
\hline HP_XIAN(-3) & 0.06 & 0.16 & 0.35 & 0.72 \\
\hline HP_XIAN(-4) & -0.37 & 0.14 & -2.67 & 0.01 \\
\hline HP_XIAN(-5) & 0.22 & 0.13 & 1.66 & 0.10 \\
\hline HP_XIAN(-6) & -0.26 & 0.14 & -1.93 & 0.06 \\
\hline HP_XIAN(-7) & 0.28 & 0.14 & 2.05 & 0.04 \\
\hline HP_XIAN(-8) & 0.18 & 0.14 & 1.34 & 0.19 \\
\hline HP_XIAN(-9) & 0.00 & 0.14 & 0.01 & 0.99 \\
\hline HP_XIAN(-10) & -0.03 & 0.12 & -0.22 & 0.83 \\
\hline HP_LANZHOU(-1) & 0.99 & 0.11 & 9.32 & 0.00 \\
\hline HP_LANZHOU(-2) & -0.25 & 0.15 & -1.67 & 0.10 \\
\hline HP_LANZHOU(-3) & 0.08 & 0.14 & 0.58 & 0.56 \\
\hline HP_LANZHOU(-4) & -0.10 & 0.13 & -0.78 & 0.44 \\
\hline HP_LANZHOU(-5) & 0.03 & 0.13 & 0.21 & 0.83 \\
\hline HP_LANZHOU(-6) & 0.06 & 0.12 & 0.50 & 0.62 \\
\hline HP_LANZHOU(-7) & -0.41 & 0.13 & -3.14 & 0.00 \\
\hline HP_LANZHOU(-8) & 0.50 & 0.15 & 3.36 & 0.00 \\
\hline HP_LANZHOU(-9) & -0.26 & 0.16 & -1.64 & 0.11 \\
\hline HP_LANZHOU(-10) & -0.05 & 0.10 & -0.46 & 0.64 \\
\hline t & 0.00 & 0.00 & -3.49 & 0.00 \\
\hline Constant & 0.46 & 0.23 & 1.98 & 0.05 \\
\hline
\end{tabular}

Notes: Adjusted R-squared=0.96, AIC=-6.36, F-statistic=121, DW=2.00.

Table-5: The Toda-Yamamoto Granger Causality Tests

\begin{tabular}{|l|l|l|l|l|l|l|l|l|}
\hline $\mathrm{H}_{0}$ & Wald- $\chi^{2}$ & $\mathrm{DF}$ & $\mathrm{k}$ & $\mathrm{F}$ & Adj. R & AIC & ARCH(8) & Ramsey(1) LR \\
\hline HP_LANZHOU to HP_XIAN & $654(0.00)$ & 9 & 9 & 198 & 0.97 & -6.46 & $17.6(0.02)$ & $0.18(0.67)$ \\
\hline HP_XIAN to HP_LANZHOU & $218(0.00)$ & 9 & 9 & 121 & 0.96 & -6.36 & $2.34(0.97)$ & $0.10(0.75)$ \\
\hline
\end{tabular}


Notes: The lag length $k$ was selected using AIC. We preset $k$ at two to twelve [13]. Assume that the data contained the maximal order of integration $d$ at one, the study estimated the $\operatorname{VAR}(k+1)$ system. The study estimated the Wald- $\chi^{2}(k)$ in order to test for $H_{0}$ (no Granger causality). DF denotes the degree of freedom. ARCH is the LM statistic for no ARCH. Ramsey denotes the Ramsey RESET $F$-statistic for constancy in the VAR model [14]. p-values in parentheses.

\section{Concluding Remarks}

New house prices in Xi'an and Lanzhou had indeed provided short-run dynamics to each other's markets. We attribute this to close geographical space, active trading activities, and frequent demographic movements. We found a feedback effect. We could expect that these short-run dynamics will help the formation of a long-run connection. In the short run, gaining from a home portfolio between these two cities is impossible. The Toda-Yamamoto test does not depend on the property of unit root and cointegration, although it is unable to reveal short-run elasticitic effects.

\section{REFERENCES}

1. Gabriel, S. A., Mattey, J. P., \& Wascher, W. L. (1999). House Price Differentials and Dynamics: Evidence from the Los Angeles and San Francisco. Economic Review, 1), 3-22.

2. Meen, G. (1999). Regional House Prices and the Ripple Effect: A New Interpretation. Housing Studies, 14(6), 733-753.

3. Gallet, C. A. (2004). Housing Market Segmentation: An Application of Convergence Tests to Los Angeles Region Housing. Annals of Regional Science, 38(3), 551-561.

4. Stevenson, S. (2004). House Price Diffusion and Inter-Regional and Cross-Border House Price
Dynamics. Journal of Property Research, 21(4), 301-320.

5. Quigley, J. M. (2008). European Metropolitan Housing Markets - Edited by Åke E. Andersson, Lars Pettersson and Ulf Strömquist. Papers in Regional Science, 87(4), 628-630.

6. Toda, H. Y., \& Yamamoto, T. (1995). Statistical Inference in Vector Autoregressions with Possibly Integrated Processes. Journal of Econometrics, 66(1/2), 225-250.

7. Granger, C. W. J. (1969). Investigating Causal Relations by Econometric Models and CrossSpectral Methods. Econometrica, 37(3), 424-438.

8. Dickey, D. A., \& Fuller, W. A. (1979). Distribution of the Estimators for Autoregressive Time Series with a Unit Root. Journal of the American Statistical Association, 74(386), 427-431.

9. Phillips, P. C. B., \& Perron, P. (1988). Testing for a Unit Root in Time Series Regression. Biometrika, 75(2), 335-346.

10. NBSC. (2020). National Data: Monthly Data House Price Indices for Seventy Cities. Available from: //data.stats.gov.cn/easyquery.htm?cn=E0104\&zb= A0108\&reg $=610100 \& s j=202010>$.

11. Ng, S., \& Perron, P. (2001). Lag Length Selection and the Construction of Unit Root Tests with Good Size and Power. Econometrica, 69(6), 1519-1554.

12. Hendry, D. F., \& Juselius, K. (2000). Explaining Cointegration Analysis: Part I. Energy Journal, 21(1), 1-42.

13. Ng, S., \& Perron, P. (1995). Unit Root Tests in Arma Models with Data Dependent Methods for the Selection of the Truncation Lag. Journal of the American Statistical Association, 90(429), 268281.

14. Ramsey, J. B. (1969). Tests for Specification Errors in Classical Linear Least Squares Regression Analysis. Journal of the Royal Statistical Society, Series B, 31(350-371. 